\title{
Risk Management in Crowdsourcing-Based Business Ecosystems
}

\author{
Suchita Nirosh Kannangara and Peter Uguccioni
}

\author{
" Risk comes from not knowing what you're doing." \\ Warren Buffet \\ Business magnate, investor, and philanthropist
}

\begin{abstract}
The benefits of crowdsourcing are enabled by open environments where multiple external stakeholders contribute to a firm's outcomes. However, crowdsourcing typically has been examined as a general process and not from the specific perspective of a mechanism for driving value creation and capture within a business ecosystem. In this conceptual article, we highlight this research gap by examining crowdsourcing from a business ecosystem perspective and by identifying the inherent business risks in crowdsourcing-based business ecosystems. We apply the concept of ecosystem health to the crowdsourcing context, in terms of how firms create and capture value, and we examine the methods by which these firms can maximize health by mitigating risk in crowdsourcing-based business ecosystems.
\end{abstract}

\section{Introduction}

Crowdsourcing has emerged as a new approach to innovation that leverages the potential of the "collective brain" to broaden the scope of open R\&D (Traitler et al., 2011; tinyurl.com/lej7dkm). As originally defined, it is "the act of a company or institution taking a function once performed by employees and outsourcing it to an undefined (and generally large) network of people in the form of an open call" (Howe, 2006a; tinyurl.com/ yfwtk2d). In order to build a foundation to both create and capture value equitably from a crowd, companies need to understand the elements of crowdsourcing and define their business models accordingly.

For firms engaging in crowdsourcing, the benefits are enabled by open environments where multiple external stakeholders contribute to the firm's outcomes. Thus, a firm is able to capture value through ideas and innovations contributed from outside the firm. For firms that are looking at producing innovative products at low cost, crowdsourcing is "the new pool of cheap labor" (Howe, 2006b; tinyurl.com/lxbf7).
However, despite the potential benefits, firms may be hesitant to use crowdsourcing because a dependency on external knowledge can also be a significant source of risk (Feller et al., 2012; tinyurl.com/l8oxsle). In this conceptual article, we examine how this risk may be managed by taking a business ecosystem perspective. In particular, we explore the concept of ecosystem health (cf. Iansiti and Levien, 2002; tinyurl.com/07s40k9) as a mechanism for risk management.

The article is organized as follows. First, we briefly summarize literature that describes business ecosystems. Next, we map the business ecosystem concept against the practice of crowdsourcing to develop the concept of a crowdsourcing-based business ecosystem. We then examine the approaches that can help management teams mitigate risk and maintain the health of such ecosystems using crowdsourcing. Finally, we offer conclusions and identify avenues for future research.

Through this article, managers, innovators, and entrepreneurs will be better able to comprehend how to shape their crowdsourcing environment by reducing 


\section{Risk Management in Crowdsourcing-Based Business Ecosystems}

\section{Suchita Nirosh Kannangara and Peter Uguccioni}

risk. Researchers will be able to identify future research areas and build effective crowdsourcing models to improve the quality of risk management.

\section{Business Ecosystems}

Ever since the term "business ecosystem" was introduced by Moore (1993; tinyurl.com/cygzy6o), the topic has gained important recognition in business model discourse (for example, see Moore, 2005: tinyurl.com/5j7jux and many articles in this publication). There are various definitions of the term, but practitioners generally agree that a business ecosystem features companies interacting both cooperatively and competitively around a common platform to meet market requirements (Muegge, 2011; timreview.ca/article/495). Muegge defines a business ecosystem as a "field of economic actors whose individual business activities, anchored around a platform, share in some large measure the outcome of the whole ecosystem".

The major difference between business ecosystems and business networks is the variety of actors (Heikkilä and Kuivaniemi, 2012; timreview.ca/article/564). Typically, business networks are groups of firms working together to address market needs, whereas business ecosystems include not only partners but also actors such as complementors, competitors, customers, etc. (Heikkilä and Kuivaniemi, 2012: timreview.ca/article/564; Bloom and Dees, 2008: tinyurl.com $/ \mathrm{mkq} 33 \mathrm{~km}$ ). For example, in some cases, creating a business ecosystem can be a means for a company to access specific knowledge or capabilities that it does not itself possess or wish to develop, but are possessed by a competitor (Heikkilä and Kuivaniemi, 2012; timreview.ca/article/564).

Firms create business ecosystems to coordinate innovation with different contributors and partners within different market segments (Chesbrough, 2006; tinyurl.com/ d5aaxah). Not every firm has all the resources, competencies, and knowledge to output complete solutions for customer needs (Traitler et al., 2011; tinyurl.com/mkejq69). Therefore, to solve a customer's problem, a firm may require the participation of a few other firms with knowledge and expertise in their own innovation domains. The organizational and governance structures of a business ecosystem helps these companies work together and manage their "distributed creativity" (Moore, 2005; tinyurl.com/5j7jux).

Business ecosystems can enable value-creating actors to respond rapidly and effectively to market changes by capturing value (Adegbesan, 2009; tinyurl.com/kgks23r).
However, different roles played by different ecosystem actors will be needed for the ecosystem to function effectively. The keystone organization orchestrates the business ecosystem and holds a leadership role in managing its activities (Iansiti and Levien, 2004a; tinyurl.com/7t4xgvn). The keystone organization also provides the platform: the technological building block for innovation and operations (Iansiti and Levien, 2004b; tinyurl.com/nmfpyms). Other participants include niche players, who are the focused actors in a business ecosystem. They provide rapid innovation in the niche areas of their expertise and contribute to the overall value proposition of the ecosystem (Iansiti and Levien, 2004a; tinyurl.com/7t4xgvn).

So how does a keystone create a productive and sustainable business ecosystem? A keystone should not only implement strategies to pursue their own goals but also strategies to maintain the overall health of the ecosystem. Iansiti and Levien (2002; tinyurl.com/o7s4ok9) introduced health as an overall performance indicator of business ecosystems; they focus on robustness, productivity, and niche creation as the determinants of overall business ecosystem health. Robustness is the ability of an ecosystem to face and survive disruptions. In order to provide durable benefits for its actors, an ecosystem should encourage endurance to survive changes in the market using a stable platform. Ecosystem robustness enhances the ability to enjoy relative predictability of the outcomes in the innovation process. Productivity is the efficiency of the ecosystem in generating new innovation (Iansiti and Levien, 2002; tinyurl.com/07s4ok9). Ecosystem actors must benefit from their affiliation to the ecosystem and capture value. Thus, productivity is considered a determinant of ecosystem health because it reflects the importance of converting inputs from ecosystem actors into valuable outputs. Niche creation encourages diversity within ecosystems; an ecosystem must have meaningful diversity to foster new valuable innovation. Stagnant ecosystems that do not create valuable innovation will urge actors to find niches in alternative ecosystems.

\section{Promoting Health in Crowdsourcing-Based Business Ecosystems}

As in business ecosystems, a variety of actors make a crowdsourcing process successful. The aggregation of a crowd and other types of actors, such as solver brokerages (i.e., intermediary who facilitate innovation exchanges between organizations and crowds) and material suppliers, work together to execute the crowdsourcing process. The presence of a platform is also a 


\title{
Risk Management in Crowdsourcing-Based Business Ecosystems
}

\author{
Suchita Nirosh Kannangara and Peter Uguccioni
}

key ingredient in the crowdsourcing process (Vukovic, 2009; tinyurl.com/qzc4d83). Thus, we can conceive most instances of crowdsourcing as a particular type of business ecosystem that uses a crowdsourcing process to drive collaborative innovation between different actors using a common platform.

The success of any business ecosystem depends on the collective health of the actors that influence innovation (Iansiti and Levien, 2004a; tinyurl.com/7t4xgvn). Thus, in viewing the crowdsourcing process from a business ecosystem perspective, we expect the benefits of a crowdsourcing process to contribute to the health of an ecosystem through the actions of its constituent actors. In Table 1, we map Iansiti and Levien's (2002; tinyurl.com/07s4ok9) determinants of ecosystem health to the benefits of the crowdsourcing process in a crowdsourcing-based business ecosystem. These relationships highlight how crowdsourcing contributes to ecosystem health, but also help identify where risks might arise in the ecosystem.

Just like any other business ecosystem, crowdsourcingbased ecosystems have business risks. Table 1 helps us understand how the benefits of crowdsourcing contribute to ecosystem health. Efforts must be made to capture these benefits by reducing any ecosystem risks, thereby maintaining good health in crowdsourcing ecosystems. Some of these risks may be common to all business ecosystems, but others may be unique to crowdsourcing-based business ecosystems generally or specific instances of such ecosystems. Control measures are required to manage these risks while capturing the benefits of crowdsourcing in the ecosystem.

\section{Managing Risk in Crowdsourcing-Based Business Ecosystems}

Smith (2013; timreview.ca/article/685) analyzed the business risks that need to be considered by firms when entering or participating in a business ecosystem, and he recommended a risk management strategy to be used in such cases, depending on the type of ecosystem being considered. Here, we extend this risk management perspective by recommending an approach aimed at managing the risks of participation in a crowdsourcingbased business ecosystem.

Our recommended strategy is inspired by business management research, which quantifies risk as the product of probability and impact of risk. Thus, a risk can be mitigated by reducing the probability that it will occur or reducing its impact, or both. We adopted Iansiti and Levien's (2004a; tinyurl.com/7t4xgvn) health determinants and factors as measurements that demonstrate the impact of events that affect an ecosystem. We define probability aspects of risk management by considering how crowdsourcing affects the likelihood of each of the risk elements that apply to the ecosystem and how these risks can be managed to gain benefits of crowdsourcing to maintain ecosystem health.

From the crowdsourcing and business ecosystem literature, we identified eight risk categories:

\section{Relationship complexity \\ (Purdy et al., 2012; tinyurl.com/bs9n5h2)}

\section{Control/effectiveness}

(Koenig, 2012; tinyurl.com/cck69qa)

\section{Coopetition}

(Koenig, 2012; tinyurl.com/cck69qa)

\section{Keystone/actor interdependence}

(Koenig, 2012; tinyurl.com/cck69qa;

Adner, 2012: tinyurl.com/lf7yxcs)

\section{Replication of business model}

(Koenig, 2012; tinyurl.com/cck69qa)

\section{Loss of know-how}

(Elmquist et al., 2009; tinyurl.com/ndatchc)

\section{Loss of certainty in results}

(Felstiner, 2010: tinyurl.com/myh2t76;

Trompette et al., 2008: tinyurl.com/8q3uvs7)

\section{Intellectual property risks \\ (Felstiner, 2010; tinyurl.com/myh2t76)}

In the subsections that follow, we describe each of these categories of risk from the perspective of crowdsourcing-based business ecosystems. Then, in Table 2, we show how crowdsourcing affects the probability of each type of risk and which of Iansiti and Levien's (2004a; tinyurl.com/7t4xgvn) health metrics are most directly impacted. We also discuss and list crowdsourcing management strategies that may reduce the probability or impact of each type of risk. 


\section{Risk Management in Crowdsourcing-Based Business Ecosystems}

Suchita Nirosh Kannangara and Peter Uguccioni

Table 1. Benefits of crowdsourcing to ecosystem health

\begin{tabular}{|c|c|c|}
\hline $\begin{array}{l}\text { Ecosystem } \\
\text { Health } \\
\text { Determinant }\end{array}$ & Factor & Benefits of Crowdsourcing to Ecosystem Health \\
\hline \multirow[t]{2}{*}{ Niche creation } & Variety & $\begin{array}{l}\text { Participants come from different backgrounds and occupy } \\
\text { different niches in the crowd. The range of new ideas from these } \\
\text { diverse sources provide the ecosystem multiple opportunities to } \\
\text { create and capture value. }\end{array}$ \\
\hline & Value creation & $\begin{array}{l}\text { Ideas generated by the crowd may allow ecosystem actors to } \\
\text { brainstorm on new innovative areas. }\end{array}$ \\
\hline \multirow[t]{3}{*}{ Productivity } & Total factor productivity & $\begin{array}{l}\text { Ecosystem actors need to assure that the productivity of their } \\
\text { crowd participants creates more additional value for the } \\
\text { ecosystem than the capital employed in the innovation process. }\end{array}$ \\
\hline & $\begin{array}{l}\text { Productivity } \\
\text { improvements }\end{array}$ & $\begin{array}{l}\text { Motivation and incentives for the crowd will enable them the } \\
\text { ability to contribute ideas/solutions with much interest. The } \\
\text { crowdsourcing process is low cost, thus it will reduce the R\&D } \\
\text { expenditure in the ecosystem. }\end{array}$ \\
\hline & Delivery of innovations & $\begin{array}{l}\text { Governance models and crowd incentives and motivation } \\
\text { ensures that the crowd will deliver new ideas and viable } \\
\text { solutions. The delivery of new ideas provides ecosystem actors to } \\
\text { start R\&D and implement them into products. }\end{array}$ \\
\hline \multirow[t]{5}{*}{ Robustness } & Survival Rates & $\begin{array}{l}\text { This attribute measures how long actors stay with the ecosystem. } \\
\text { Incentives for the crowd is a good retention mechanism to keep } \\
\text { the crowd in the ecosystem. }\end{array}$ \\
\hline & Persistence of structure & $\begin{array}{l}\text { The relationship among crowd members and the focal firm must } \\
\text { be persistent. Incentives and motivations for the crowd helps to } \\
\text { retain the crowd for future innovation processes. Retaining the } \\
\text { crowd helps to continuously generate novel ideas and continue } \\
\text { the innovation process. Retaining the crowd ensures the } \\
\text { ecosystem structure is not changed by recruiting other crowds to } \\
\text { the ecosystem. }\end{array}$ \\
\hline & Predictability & $\begin{array}{l}\text { The crowdsourcing platform enables the interaction between the } \\
\text { crowd and the keystone. The platform does not change even } \\
\text { though the crowd may change. The core of the ecosystem is not } \\
\text { affected by a change in ecosystem actors. }\end{array}$ \\
\hline & Limited obsolescence & $\begin{array}{l}\text { Most of the installed base or investment in technology or } \\
\text { components used in the crowdsourcing platform finds } \\
\text { continued use after dramatic changes to the platform such as } \\
\text { different crowds joining the platform. }\end{array}$ \\
\hline & Continuity & $\begin{array}{l}\text { The crowd will continuously generate new ideas and innovations } \\
\text { for the firm as the platform continuously provides incentives for } \\
\text { the crowd. These incentives promote crowd retention for future } \\
\text { innovation activities, which provides further continuity. }\end{array}$ \\
\hline
\end{tabular}




\section{Risk Management in Crowdsourcing-Based Business Ecosystems}

\section{Suchita Nirosh Kannangara and Peter Uguccioni}

\section{Relationship complexity}

Purdy and colleagues (2012; tinyurl.com/bs9n5h2) described relationship complexity risk in terms of the complexity and entropy in managing relationships between actors within the ecosystem and the keystone. In a crowdsourcing context, the increased number of participants and diversity within the crowd can increase the probability of risk in managing relationships with the crowd. Incentives offered to the crowd by the keystone can contribute goodwill to the relationship and build trust. Firms can also have internal champions within the crowd to run the course of the innovation process by guiding the crowd. This role will help the crowd to have a better understanding of the requirements needed by the other actors of the ecosystem.

\section{Control/effectiveness}

Control risk refers to the effectiveness of the control measures, whether centrally located or distributed throughout the ecosystem (Koenig, 2012; tinyurl.com/ cck69qa). Control of a crowd in any measure can seem counter-intuitive; so much of crowdsourcing research focuses on freeing participants from control and allowing broader participation that governing bodies may have historically screened out (Nambisan, 2009; tinyurl.com/pfmymbk). Effective crowd monitoring and effective solution evaluation can include control measures provided they do not act as crowd inhibitors.

\section{Coopetition}

Coopetition, as described by Koenig (2012; tinyurl.com/ cck69qa), refers to the effects or impact of co-innovating with competitors within an ecosystem. Crowdsourcing within ecosystems focuses on innovation around "challenges" that may introduce competitive risk. Using common/shared incentives to recruit and retain membership is another method found in crowdsourcing literature to manage competitive instincts. Strong enforcement of crowd charter rules and agreements can reduce the negative impacts of competitors getting to know internal knowledge shared within an ecosystem.

\section{Keystone/actor interdependence}

Keystone/actor interdependence was highlighted by Adner (2006; tinyurl.com/bpj4syf) as a risk due to the uncertainties that can occur while coordinating with actors (Smith, 2013; timreview.ca/article/685). This means some actors may need to wait until other actors succeed in their contribution. The innovation's success depends not only on a firm's successful completion of its contribution but on the successful development of other act- ors' contributions as well. In crowdsourcing, the keystone relies on the crowd as a supplier of ideas or solutions. The crowd has less at stake relative to the keystone. They might not show interest in contributing or cheat in the process of gaining incentives from the platform (Hirth et al., 2011; tinyurl.com/l32exln). This risk can cause project delays and disrupt the innovation process of the whole ecosystem. Focused and measured "challenges", cheat-detection mechanisms, and recruiting methods that carefully manage incentives and motivations within the crowd can reduce the probability of this type of risk, and can reduce the impact of its consequences.

\section{Replication of business model}

Within local markets, there can be a risk of replicating business models (Koenig, 2012; tinyurl.com/cck69qa), and this risk is exacerbated by the presence of crowds within an ecosystem. With many diverse members, crowds may gain access to business model data or related insights through the crowdsourcing tasks. Careful and measured "challenges" that do not reveal business model sensitivities can reduce the probability of copycats emerging. Charter enforcement can also manage the impact by invoking enforcement rules against its own members.

\section{Loss of know-how}

Loss of know-how can also be a risk introduced by the presence of crowds within an ecosystem. The keystone's knowledge and internal resources are fundamental to an innovation process. When the crowd is integrated to the innovation process, they may acquire some of the a keystone's know-how. The risk of integrating the crowd is that crowd members could use a firm's know-how for their own purposes or even sell it to competitors (Elmquist et al., 2009; tinyurl.com/ndatchc). Crowd monitoring and evaluation mechanisms and strict quality assurance of solutions ensure that positive crowdsourcing outcomes are integrated back into the ecosystem.

\section{Loss of certainty in results}

Loss of certainty of results is always a possibility when the crowd does not feel the responsibility and accountability for solving tasks. Even the most committed crowd worker will have less at stake than a formal employee (Felstiner, 2010; tinyurl.com/myh2t76). By putting higher-qualification restrictions to govern the crowd or by using multiple crowd actors to work on a single task increases the probability of success through the innovation process. 


\section{Risk Management in Crowdsourcing-Based Business Ecosystems}

Suchita Nirosh Kannangara and Peter Uguccioni

Table 2. Crowdsourcing strategies to reduce risks in crowdsourcing-based business ecosystems

\begin{tabular}{|c|c|c|c|}
\hline Risk Category & $\begin{array}{l}\text { How Crowdsourcing } \\
\text { Affects Probability }\end{array}$ & $\begin{array}{l}\text { Most Direct } \\
\text { Health } \\
\text { Determinant } \\
\text { Impacted }\end{array}$ & $\begin{array}{l}\text { Crowdsourcing Strategy to } \\
\text { Reduce Risk }\end{array}$ \\
\hline $\begin{array}{l}\text { Relationship } \\
\text { complexity }\end{array}$ & $\begin{array}{l}\text { Can introduce more } \\
\text { complexity and } \\
\text { more uncertainty }\end{array}$ & $\begin{array}{l}\text { - Productivity } \\
\text { - Robustness } \\
\text { - Niche creation }\end{array}$ & $\begin{array}{l}\text { - Internal champions to } \\
\text { guide the crowd } \\
\text { - Incentives for crowd } \\
\text { - Crowd governance }\end{array}$ \\
\hline $\begin{array}{l}\text { Control/ } \\
\text { effectiveness }\end{array}$ & $\begin{array}{l}\text { Control is less } \\
\text { attractive in crowds }\end{array}$ & $\begin{array}{l}\text { - Productivity } \\
\text { - Robustness }\end{array}$ & $\begin{array}{l}\text { - Crowd monitoring } \\
\text { - Solution evaluations }\end{array}$ \\
\hline Coopetition & $\begin{array}{l}\text { Larger mix and } \\
\text { diversity of } \\
\text { participants }\end{array}$ & - Niche creation & $\begin{array}{l}\text { - Common/shared } \\
\text { incentive } \\
\text { - Charter enforcement } \\
\text { - Focused challenge }\end{array}$ \\
\hline $\begin{array}{l}\text { Keystone/actor } \\
\text { interdependence }\end{array}$ & $\begin{array}{l}\text { Crowdsourcing } \\
\text { requires proxy, but } \\
\text { not internal control }\end{array}$ & $\begin{array}{l}\text { - Productivity } \\
\text { - Robustness }\end{array}$ & $\begin{array}{l}\text { - Focused challenge } \\
\text { - Cheat detection } \\
\text { - Common/shared } \\
\text { incentive }\end{array}$ \\
\hline $\begin{array}{l}\text { Replication of } \\
\text { business model }\end{array}$ & $\begin{array}{l}\text { Larger number and } \\
\text { diversity of } \\
\text { participants }\end{array}$ & - Niche creation & $\begin{array}{l}\text { - Charter enforcement } \\
\text { - Focused challenge }\end{array}$ \\
\hline Loss of know-how & $\begin{array}{l}\text { Crowd actors will } \\
\text { gain access to } \\
\text { internal knowledge } \\
\text { of firms in the } \\
\text { ecosystem }\end{array}$ & - Niche creation & $\begin{array}{l}\text { - Monitoring and } \\
\text { evaluation mechanisms. } \\
\text { - Crowd monitoring }\end{array}$ \\
\hline $\begin{array}{l}\text { Loss of certainty in } \\
\text { results }\end{array}$ & $\begin{array}{l}\text { The crowd actor has } \\
\text { less at stake for not } \\
\text { contributing to the } \\
\text { innovation process }\end{array}$ & $\begin{array}{l}\text { - Productivity } \\
\text { - Robustness }\end{array}$ & $\begin{array}{l}\text { - Higher qualification } \\
\text { restrictions to govern the } \\
\text { crowd } \\
\text { - Multiple actors working } \\
\text { on a single task }\end{array}$ \\
\hline $\begin{array}{l}\text { Intellectual } \\
\text { property risks }\end{array}$ & $\begin{array}{l}\text { Crowd actors have } \\
\text { access to intellectual } \\
\text { property when } \\
\text { solving a task }\end{array}$ & - Niche creation & $\begin{array}{l}\text { - Nondisclosure policies } \\
\text { and crowdsourcing rules }\end{array}$ \\
\hline
\end{tabular}




\section{Risk Management in Crowdsourcing-Based Business Ecosystems}

\section{Suchita Nirosh Kannangara and Peter Uguccioni}

\section{Intellectual property risks}

Keystones may encounter serious intellectual property risks by assigning tasks or problem-solving challenges to an anonymous crowd. Crowd actors may have access to intellectual property within an ecosystem by completing even small tasks (Trompette et al., 2008: tinyurl.com/8q3uvs7; Felstiner, 2010: tinyurl.com/myh2t76). The platform may impose nondisclosure policies or set rules to protect proprietary material as part of an agreement when enlisting a crowd.

\section{Conclusion}

In this conceptual article we applied the perspective of business ecosystems to the process of crowdsourcing to conceptualize crowdsourcing-based business ecosystems. We described crowdsourcing and what roles actors can typically play in a crowdsourcing-based business ecosystem if they are recruited and managed by an ecosystem keystone. We reviewed the attributes a strong business ecosystem and the factors that determine its health through the participation and interaction of its actors (Iansiti and Levien, 2002; tinyurl.com/07s4ok9). These factors were used to define the impact used by risk management strategies. This article also builds on the work of Smith (2013; timreview.ca/article/685), who offered risk management strategies for entry into business ecosystems. Our risk management approach helps mitigate the risks introduced by crowdsourcing activities within a business ecosystem.

Firms should consider crowdsourcing-based business ecosystems for the purposes of low-cost $R \& D$, to generate and gather novel ideas, and to understand the latent needs of customers. To further help these firms identify and manage the risks of such an approach, future empirical research should explore and test the concepts and strategies identified in this article. Further research could examine how managing horizontal relationships in crowdsourcing-based ecosystem can enhance a firm's ability grow value in a business.

\section{About the Authors}

Nirosh Kannangara is a graduate student in the Technology Innovation Management (TIM) program at Carleton University in Ottawa, Canada. He holds a BEng in Communications Engineering, also from Carleton University. Nirosh has more than two years of experience designing software in the optical transport communication industry and currently works as a Photonics Software Engineer at Ciena Corporation.

Peter Uguccioni is a graduate student in the Technology Innovation Management (TIM) program at Carleton University in Ottawa, Canada. He holds a bachelor's degree in Computer Science from the University of Ottawa. Peter has more than 20 years of experience in software development and as a manager of technology innovation at a variety of firms in Ottawa.

Citation: Kannangara, S.N. and P. Uguccioni. 2013. Risk Management in Crowdsourcing-Based Business Ecosystems. Technology Innovation Management Review. December 2013: 32-38.

Keywords: crowdsourcing, business ecosystems, risk management, business ecosystem health 